\title{
High efficiency liposome fusion induced by reducing undesired membrane peptides interaction
}

https://doi.org/10.1515/chem-2019-0004

received March 17, 2017; accepted August 2, 2017.

Abstract: A full membrane fusion model which attains both complete lipid mixing and content mixing liposomal membranes mediated by coiled-coil forming lipopeptides LPK $\left[\mathrm{L}-\mathrm{PEG}_{12}\right.$-(KIAALKE) $_{3}$ ] and LPE [L-PEG -(EIAALEK) $_{3}$ ] is presented. The electrostatic effects of lipid anchored peptides on fusion efficiency was investigated. For this, the original amino acid sequence of the membrane bound LPK was varied at its ' $\mathrm{f}$ '-position of the helical structure, i.e. via mutating the anionic glutamate residues by either neutral serines or cationic lysines. Both $C D$ and fluorescence measurements showed that replacing the negatively charged glutamate did not significantly alter the peptide ability to form a coiled coil, but lipid mixing and content mixing assays showed more efficient liposome-liposome fusion resulting in almost quantitative content mixing for the lysine mutated analogue $\left(\mathbf{L P K}_{\mathrm{K}}\right)$ in conjunction with LPE. A mechanism is proposed for a fusion model triggered by membrane destabilizing effects mediated by the membrane destabilizing activety of LPK in cooperation with the electrostatic activity of LPE. This new insight may enlightens the further development of a promising nano carrier tool for biomedical applications.

Keywords: SNAREs mimicking; de novo design; binding affinity; membrane fusion.

\footnotetext{
*Corresponding author: Tingting Zheng, Shenzhen Key Laboratory for Drug Addiction and Medication Safety, Department of Ultrasound, Peking University Shenzhen Hospital, Shenzhen Peking UniversityThe Hong Kong University of Science and Technology Medical Center, 518036 Shenzhen, China; Supramolecular and Biomaterials Chemistry, Leiden Institute of Chemistry, Leiden University, P. O. Box 9502, 2300RA, Leiden, The Netherlands, E-mail: dr.tingting.zheng@gmail.com Yun Chen, Yu Shi: Shenzhen Key Laboratory for Drug Addiction and Medication Safety, Department of Ultrasound, Peking University Shenzhen Hospital, Shenzhen Peking University- The Hong Kong University of Science and Technology Medical Center, 518036 Shenzhen, China

Huanhuan Feng: School of Materials Science and Engineering, Harbin Institute of Technology (Shenzhen), Shenzhen, 518055, China
}

\section{Introduction}

Membrane fusion is an essential fundamental vital process in all living cells facilitating inter- and intracellular molecules transportation [1-3]. One of the most important actors in membrane trafficking, so called SNARE proteins (soluble N-ethyl maleimide sensitive factor attachment protein receptors), mediate membrane fusion is being extensively studied [4-11]. However, the molecular mechanism is still under debated. To trigger membrane fusion, a four-helix coiled-coil bundle forms between two membrane-bound SNARE protein subunits and a cytoplasmic SNARE protein subunit, forcing the two membranes within a distance of $2-3 \mathrm{~nm}$ from one another, resulting in docking of the two opposing membranes followed by lipid and content mixings $[12,13]$. Inspired by this natural and highly controlled transport mechanism, supramolecular and biomaterials chemists designed synthetic targeted membrane fusion systems in order to study the mechanism of membrane fusion at a fundamental level, aiming to explore applications in the design nanocarriers for drug delivery systems. Our previously published synthetic membrane fusion system shows an effective way of inducing liposome-liposome fusion [10,14-21]. There are three key components in the design of our fusion model, including molecular recognition composed of two complimentary coiled coil forming peptides $(\mathrm{E} / \mathrm{K})$, a flexible linker (PEG) and a lipid (L) anchor (DOPE). First is the molecular recognition part, which drives the membranes of two differently LPK- and LPE-anchored liposomes into close proximity. For this we use the complementary $\mathrm{K}$ (KIAALKE) ${ }_{3}$ and E (EIAALEK) peptides, which were designed by Litowski and Hodges (J. Biol. Chem, 2002) to form a heterodimeric coiled coil complex [13,22].\{Litowski, 2001 \#17;Marsden, 2009 \#11;Litowski, 2002 \#39\} The second component in our design is the lipid anchor DOPE (1,2-dioleoyl-sn-glycero3-phosphoethanolamine), that guarantees peptides anchoring into the lipid bilayer (Scheme 1). Third, the flexibility and rotational freedom of the peptides are ensured by covalent linking a $\mathrm{PEG}_{12}$ (poly(ethylene glycol) 


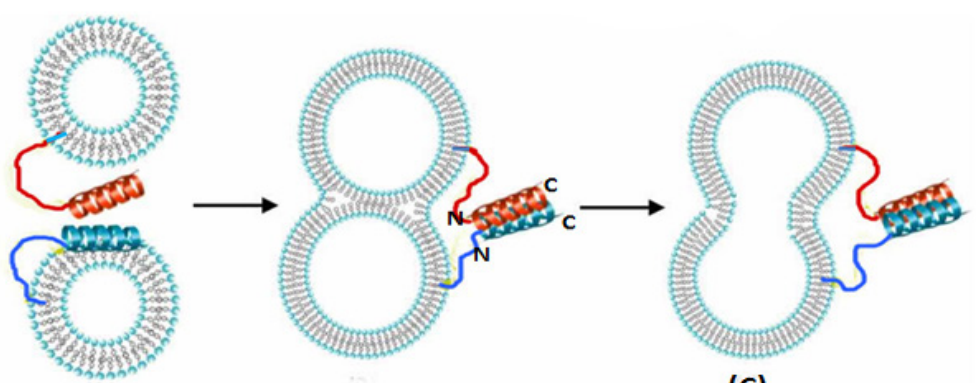

(A)

(B)

(C)

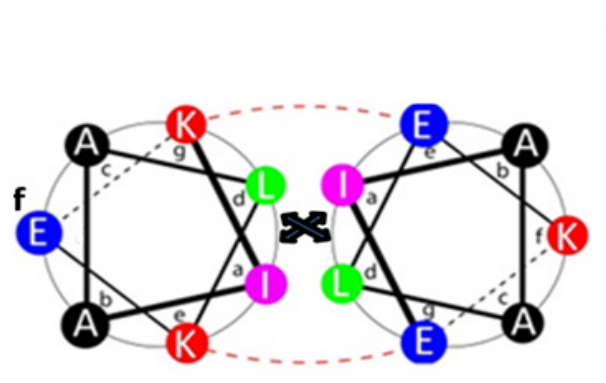

(D)



(E)

\begin{abstract}
Scheme 1: Illustration of the original concept of liposome fusion mediated by peptides ' $K$ ' [(KIAALKE) ${ }_{3}$ and 'E' [(EIAALEK) ${ }_{3}$. Liposomes (not at scale) are decorated with membrane tethered lipo-peptides, LPK (DOPE-Peg ${ }_{12}-$ K) in blue or LPE (DOPE-Peg - E) in red (A). Upon mixing them coiled-coil formation would bring the opposite liposomes in close (ca. $2 \mathrm{~nm}$ ) proximity (B), and finally leading to fusion with content mixing (C). The so-called helical wheel of the coiled coil K/E is represented by a top-down view (from N to C-terminus) of the hetero-dimer showing the mutual hydrophobic (Ile/Leu) and electrostatic (Lys/Glu) interactions (red broken lines) as well as the solvent exposed residues at the 'f' positions of the $\alpha$-helix (D). However, recent experimental data showed more asymmetric peculiarities of the membrane tethered LPE and LPK peptides: a solvated conformational poorly characterized E-peptide and an $\alpha$-helical membrane bound K-peptide. According to MD experiments the amphipathic K-peptide binds to the membrane with the side chains of the lle and Leu residues inserted near the core of the membrane, while the negatively charged glutamates at the ' $f$ '-positions of the $\mathbf{K}$-helix remain water exposed (E). To verify this MD model, the present study was undertaken.
\end{abstract}

spacer to both the membrane anchor and the N-terminal ends of the E- and K-peptides.

A driving force for the association of the two different 3-heptad peptides $\mathbf{K}$ and $\mathbf{E}$ to the hetero-dimer $\mathbf{K} / \mathbf{E}$ complex is dominated by the knob-into-hole interactions between the branched hydrophobic Ile and Leu (shown at the ' $a$ '- and ' $d$ '-positions of the helical wheel models in Scheme 1) $[19,20,23]$. Electrostatic interactions of the Glu- and Lys-side chains at positions 'e' and ' $\mathrm{g}$ ' also contribute to the stability. The ' $b$ ' and 'c' are occupied by alanine, which increases the propensity of the peptide to adopt an $\alpha$-helical configuration [24]. This coiled coil was designed to function at neutral $\mathrm{pH}$, where the side chains of all lysine residues are protonated, and hence positive charged, while the side chains of all glutamate residue residues are deprotonated and hence negatively charged.

In the original fusion model developed in the Kros group, the LPK and LPE lipo-peptides were anchored to different liposomal membranes, via PEG linkages. After mixing these two liposomes, the ability of fusion of the different membranes together could be detected by fluorescence spectroscopy. Significant membrane fusion is triggered immediately as was shown by lipid mixing end vesicular content mixing experiment [25].

Recent fluorescence-, ${ }^{31} \mathrm{P}-, \quad{ }^{15} \mathrm{~N}-\mathrm{NMR}-\quad$ and MD-spectroscopic data, however, proved asymmetric characteristics for $\mathbf{K}$ and $\mathbf{E}$-peptides [26,27]. The $\mathbf{K}$-peptide binds to the membrane, while E-peptide remains solvent exposed. CD experiments showed contrasting data for the conformational characteristics of the peptides, the K-peptide has shown to be more $\alpha$-helical than $\mathbf{E}$. Fluorescence quenching experiments with lipids labelled at different positions indicate that the amphipathic $\mathbf{K}$-molecule partly inserts into the membrane with the long helix axis cantered at a distance of 17-19 A from the bilayer centre. According to NMR, the K-peptide binds parallel to the surface of the membrane and the binding is accompanied by a perturbation of the lipid head group region of the membrane at the peptide binding site. Moreover, a positive curvature as well as a reorganized membrane composition was suggested. The ability of K-peptide, inducing membrane curvature and a locally PE 
lipid enriched membrane composition, was supported by MD experiments. Furthermore, MD data suggest that this binding mode of $\mathbf{K}$-molecules is accompanied with lipid acyl protrusions, indicating induction of unstable regions of the membrane due to a lack of cholesterol molecules.

However, so far, the essential role of the E-peptide for membrane fusion remains unclear, yet. It was also shown that activity of fusion is dependent on the lengths of the flexible PEG linkages, with an optimum defined by $\mathrm{PEG}_{12}$. The poorly defined conformation of the membrane $\mathbf{E}$-anchored peptide was proposed to act as a 'handle' in order to attract $\mathbf{K}$. Once coiled coil K/E complex is formed, it would facilitate liposome docking; destabilizing phospholipid arrangement and finally triggering membrane fusion (see Figure 1) $[26,28]$. However, it could hardly achieve $100 \%$ content mixing in that model. Therefore, it is still not 'perfect' for special assignment of a drug delivery system $[10,25,29,30]$. Tuning liposome composition does not significantly influence the efficiency of content mixing.

Interestingly, the model created by the MD simulation showed a detailed picture about the binding mode for the K-peptide showing the screening of the cationic charges by lipid phosphate groups leaving the anionic glutamates at the surface (Scheme 1E). However, this model does not explain the role of the 3-fold negatively charged E-peptide, which would be unable to bind to the glutamates of the membrane, bound $\mathbf{K}$ molecules. Therefore, we hypothesize that a more efficient membrane fusion should be triggered by replacing the negatively charged $7^{\text {th }} 14^{\text {th }} 21^{\text {st }}$ glutamic acid of $\mathbf{K}$ with neutral serines $\left(\mathbf{K}_{\mathbf{s}}\right)$ and (even better) by positively charged lysines $\left(\mathbf{K}_{\mathrm{K}}\right)$. In order to verify our theory, we synthesized these mutants of both free and lipidated peptides accordingly. $1 \mathrm{~mol} \%$ LPK peptide was bound on the surface of liposomal membrane, yielding LPK-liposome, and vice versa for LPE-liposome. Upon equimolar mixing of $\mathbf{K}$-liposome with $\mathbf{E}$-liposome in buffer $(\mathrm{pH}=7.4)$. The liposomes used were prepared from (DOPC/ $\mathrm{DOPE} / \mathrm{CH}=50: 25: 25 \mathrm{~mol} \%$ ) (DOPC is 1,2-dioleoyl-snglycero-3-phosphatidylcholine, while $\mathrm{CH}$ is cholesterol). Circular Dichroism (CD) spectroscopy showed that the structures of the mutants are similar the native ones. The ability of the mutants to form coiled coils is shown by $\mathrm{CD}$ of N-terminal acetylated peptides not influenced. CD of $\mathbf{L P K}_{\mathrm{K}} / \mathbf{L P E}$ decorated liposomes, however, showed a rather low level of coiled coils in liposomes. Contrastingly, experiments with liposomes containing LPE with mutated LPK peptides showed a rapidly increased level of fusion as was shown by time dependent lipid mixing and content mixing experiments. This study proves our hypothesis that $\mathbf{L P K}_{\mathrm{K}}$ triggers faster and more thoroughly liposome fusion with LPE liposomes, comparing with LPK $_{\mathrm{s}}$ or LPK, confirming the important electrostatic role for the cationic lysine at position ' $\mathrm{f}$ ' of the $\mathbf{K}$-helical molecule.

\section{Materials \& Methods}

\subsection{Materials}

Peptides and lipopeptides were synthesized and purified as described previously [31]. DOPE was purchased from Lipoid AG, and cholesterol was obtained from Fluka. DOPE-NBD and DOPE-LR were obtained from Avanti Polar Lipids. All other reagents and solvents were obtained at the highest purity available from Sigma-Aldrich or BioSolve Ltd. and used without further purification. Milli-Q water with a resistance of more than $18.2 \mathrm{M} \Omega / \mathrm{cm}$ was provided by a Millipore Milli- $Q$ filtering system with filtration through a $0.22 \mu \mathrm{m}$ Millipak filter.

\subsection{Liposome Preparation}

\subsubsection{Liposome for lipid mixing and DLS measurement}

Liposomes were composed of DOPC/DOPE/CH (50:25:25 mol\%). Fluorescent labelled liposomes also contained $0.5 \mathrm{~mol} \%$ LR-DOPE and NBD-DOPE. Lipid stock solutions (1 $\mathrm{mM}$ ) were prepared in chloroform. Lipopeptide stock solutions $(10 \mu \mathrm{M})$ were prepared in 1:1 (v/v) chloroform:methanol. Liposomes were prepared by drying appropriate volumes of the lipid and lipopeptide stock solutions in a $20 \mathrm{~mL}$ bottle under reduced pressure, addition of PBS buffer ( $\mathrm{pH}$ 7.4) and sonication for $\sim 5$ minutes in a bath sonicator with the water bath at $55^{\circ} \mathrm{C}$. liposome samples for DLS measurement follow the same procedure as above, but without fluorescent dyes.

\subsubsection{Liposome for content mixing}

For this assay, $1 \mathrm{mM} 1 \mathrm{~mol} \%$ Coil-E decorated liposome was prepared, encapsulating $20 \mathrm{mM}$ sulforhodamine B in $\mathrm{pH}=7.4 \mathrm{PBS}$ buffer (shortname $\mathrm{E}-\mathrm{L}_{\mathrm{RD}}$ ). $\mathrm{E}-\mathrm{L}_{\mathrm{RD}}$ was futher purified by sephadex G-100 column manually (column length $=400 \mathrm{~mm}$, diameter $=30 \mathrm{~mm}$, flow rate $=1$ drop $\mathrm{s}^{-1}$ ), yielding $0.1 \mathrm{mM}$ with $1 \mathrm{~mol} \%$ Coil-E decoration $E_{R D}-\mathrm{L}$. Meanwhile, $0.1 \mathrm{mM} 1 \mathrm{~mol} \%$ Coil-K decorated liposome was prepared as the way mentioned above (shortname $\mathrm{K}-\mathrm{L})$. 


\subsection{Experimental Methods}

FRET-based lipid mixing experiments were conducted on a Tecan X fluorometer using a 96 well plate. The z-position was $12500 \mu \mathrm{m}$, and the gain was optimized according to the amount of fluorophore in the sample. Excitation and emission slits were set at $10 \mathrm{~nm}$. The excitation wavelength was $460 \mathrm{~nm}$, and NBD emission was monitored $535 \mathrm{~nm}$. The measurements were done in room temperature. 100 $\mu \mathrm{L}$ of fluorescent and non-fluorescent liposomes were combined, and for consistent mixing the plate was shaken inside the fluorometer for 30 seconds (2mm linearly, $70 \mathrm{x}$ per minute). Data was collected every 20 seconds for at least 1 hour. Using $0.5 \mathrm{~mol} \%$ of each fluorophore in the fluorescent liposomes and mixing fluorescent and nonfluorescent liposomes in a 1:1 molar ratio the increase in NBD fluorescence is proportional to lipid mixing. The data was calibrated to show the percentage of liposomes that have undergone lipid mixing $(\operatorname{LM}(\%))$ by $\operatorname{LM}(\%)=$ $100 \% \times\left(I_{t}-I_{0}\right) /\left(I_{\max }-I_{0}\right)$, where $I_{0}$ is the NBD intensity of 1:1 (v/v) fluorescent liposomes: PBS, and $\mathrm{I}_{\max }$ is the NBD intensity of liposomes of the same concentration prepared using an equimolar mixture of fluorescent and nonfluorescent stock solutions.[15] $\mathrm{I}_{0}$ and $\mathrm{I}_{\max }$ were monitored with time as they are temperature sensitive. This assay only detects fusion between the original liposomes. e.g. if two pre-fused liposomes fuse, the distance between the fluorophores does not change so the event is not detected.

For content mixing assay, the fluorescence signal of the sulforhodamine $\left(\lambda_{\mathrm{em}}=580 \mathrm{~nm}\right)$ was detected once upon 1:1 mixing $\mathrm{E}_{\mathrm{RD}}-\mathrm{L}$ (100ul) with K-L (100 ul). The increase of sulforhodamine B fluorescence is due to a relief of selfquenching following by content mixing, named Ft. The F0 is $100 \mathrm{uL}$ ERD-L with $100 \mathrm{ul} \mathrm{PBS}$, and the $\mathrm{F}_{100}$ is the fluorescence signal intensity after addition of $1 \%(\mathrm{w} / \mathrm{v})$ Triton X-100 in PBS into the $\mathrm{E}_{\mathrm{RD}}-\mathrm{L}+\mathrm{K}-\mathrm{L}$ well. And the content mixing is calculated by $\mathrm{CM}(\%)=100 \% \times\left(\mathrm{F}_{\mathrm{t}}-\mathrm{F}_{0}\right) /\left(\mathrm{F}_{\max }-\mathrm{F}_{0}\right)$. All the data are calculated from 3 times measurements.

For either lipid mixing or content mixing, the standard deviations $(\sigma)$ are calculated by the formula: $\sigma=\sqrt{\frac{1}{N} \sum_{i=1}^{N}\left(x_{i}-\mu\right)^{2}}$, where $\mu=\frac{1}{N} \sum_{i=1}^{N} \mathrm{x}_{\mathrm{i}}\left(\mathrm{x}_{\mathrm{i}}\right.$ is the fluorescence intensity from measurement, $\mathrm{N}$ is the number of measurement. In this study, $\mathrm{N}=3$ ).

Circular dichroism spectra were obtained using a Jasco J-815 spectropolarimeter equipped with a peltiercontrolled thermostatic cell holder (Jasco PTC-423S). Spectra were recorded from $260 \mathrm{~nm}$ to $200 \mathrm{~nm}$ in a quartz cuvette with $5.0 \mathrm{~mm}$ pathlength at $25^{\circ} \mathrm{C}$. Data were collected at $1.0 \mathrm{~nm}$ intervals with a $1 \mathrm{~nm}$ bandwidth and $1 \mathrm{~s}$ readings. Each spectrum was the average of 5 scans. The spectra had a baseline of plain liposomes in TES buffer subtracted. The ellipticity is given as the mean residue molar ellipticity, [ $\theta]\left(10^{3} \mathrm{deg} \mathrm{cm}^{2} \mathrm{dmol}^{-1}\right)$, calculated from $[\theta]=\left(\theta_{o b s} \times M R W\right) /(10 \times 1 \times c)$, where $\theta_{o b s}$ is the observed ellipticity in millidegres, MRW is the mean residue molecular weight (i.e. the molecular weight of the peptide divided by the number of amino acid residues), 1 is the path length of the cuvette in $\mathrm{cm}$ and $\mathrm{c}$ is the peptide concentration in $\mathrm{mg} \mathrm{mL}^{-1}$ [29].

A $1.0 \mathrm{~mm}$ quartz cuvette and a final concentration of $200 \mu \mathrm{M}$ peptide in PBS ( $\mathrm{pH}=7.4)$. Spectra were recorded from $250 \mathrm{~nm}$ to $200 \mathrm{~nm}$ at $25^{\circ} \mathrm{C}$. Unless stated otherwise, data points were collected with a $0.5 \mathrm{~nm}$ interval with a 1 $\mathrm{nm}$ bandwidth and scan speed of $1 \mathrm{~nm}$ per second. Each spectrum was an average of 5 scans. For analysis, each spectrum had the appropriate background spectrum (buffer or 50\% TFE) subtracted.

For determination of the coiled coil thermal dissociation constant, temperature dependent CD spectra were obtained using an external temperature sensor immersed in the sample [32,33]. The temperature was controlled with the internal sensor and measured with the external sensor. A $10 \mathrm{~mm}$ quartz cuvette was used, and the solutions were stirred at $900 \mathrm{rpm}$. Spectra were recorded from $250 \mathrm{~nm}$ to $200 \mathrm{~nm}$, with data collected at $0.5 \mathrm{~nm}$ intervals with a $1 \mathrm{~nm}$ bandwidth and a scan speed of $1 \mathrm{~nm}$ per second. The temperature range was $6^{\circ} \mathrm{C}$ to $96^{\circ} \mathrm{C}$ with a temperature gradient of $2.0^{\circ} \mathrm{C}$ per minute and a $60 \mathrm{~s}$ delay after reaching the set temperature. The spectrum of PBS at $6^{\circ} \mathrm{C}$ (average of 5 scans) was subtracted from each spectrum. All the thermal unfolding curves were analyzed using a two-state conformation transition model [34,35].

The data were analysed using a two-state unfolding model to determine the fraction folded using Eqn. (2),

$$
\mathrm{F}_{\mathrm{f}}=\left([\Theta]-[\theta]_{\mathrm{U}}\right) /\left([\Theta]_{\mathrm{F}}-[\theta]_{\mathrm{U}}\right)
$$

Where $[\theta]$ is the observed molar ellipticity, $[\theta] \mathrm{U}$ is the ellipticity at $222 \mathrm{~nm}$ of the denatured state, as determined from the plateau of the ellipticity vs. temperature curve, and $[\theta] \mathrm{F}$ is the ellipticity at $222 \mathrm{~nm}$ of the folded state at that temperature as determined from a linear fit of the initial stages of the ellipticity vs. temperature curve. The fraction unfolded, $F_{U}$, was calculated by Eqn. (3),

$$
\mathrm{F}_{\mathrm{U}}=1-\mathrm{F}_{\mathrm{f}}
$$

The dimer dissociation constant in the transition zone was calculated using Eqn. (4),

$$
\mathrm{K}_{\mathrm{U}}=2 \mathrm{P}_{\mathrm{t}} \mathrm{F}_{\mathrm{U}}^{2} / \mathrm{F}_{\mathrm{f}}
$$

Pt is the total peptide concentration. By taking the derivative of the $\ln \left(\mathrm{K}_{\mathrm{U}}\right)$ vs. temperature and using this in the van't Hoff equation, Eqn. (5), the change in enthalpy 
associated with unfolding with temperature can be plotted:

$$
\Delta \mathrm{H}_{\mathrm{U}}=\mathrm{RT}^{2} \times\left(\mathrm{d} \ln \left(\mathrm{K}_{\mathrm{U}}\right) / \mathrm{dT}\right)
$$

The gradient of enthalpy vs. temperature plot $\Delta \mathrm{Cp}$, is the difference in heat capacity between the folded and unfolded forms, and can be used in the Gibbs-Helmholtz equation adapted to monomer-dimer equilibrium, Eqn. (6), to obtain the Gibbs free energy of unfolding as a function of temperature by least-squares fitting,

$$
\Delta \mathrm{G}_{\mathrm{U}}=\Delta \mathrm{H}_{\mathrm{m}}\left(1-\mathrm{T} / \mathrm{T}_{\mathrm{m}}\right)+\Delta \mathrm{C}_{\mathrm{p}}\left[\mathrm{T}-\mathrm{T}_{\mathrm{m}}-\mathrm{Tln}\left(\mathrm{T} / \mathrm{T}_{\mathrm{m}}\right)\right]-\mathrm{RT} \ln \left[\mathrm{P}_{\mathrm{t}}\right]
$$

$\mathrm{T}_{\mathrm{m}}$ and $\mathrm{H}_{\mathrm{m}}$ are the temperature and enthalpy at the midpoint of the transition at which the fraction of monomeric peptide is 0.5 [15].

Ethical approval: The conducted research is not related to either human or animal use.

\section{Results}

\subsection{Peptide interaction study in solution}

\subsubsection{Peptide design}

To investigate whether electrostatic interactions have an effect on the $\mathbf{K}$ - and $\mathbf{E}$-peptide mediated membrane fusion and to test the postulated role of the negatively charged glutamates at position ' $\mathrm{f}$ ', two new sequences were synthesized with either the non-charged serine (S) or the positive charged lysine on position ' $\mathrm{f}$ ', denoted $\mathbf{K}_{\mathrm{S}}$ and $\mathbf{K}_{\mathrm{K}}$ ', respectively (see Table 1 and supplemental information, Figure S1). For the interpretation of the electrostatic effects on the fusion efficiency in terms of a plausible fusion mechanism, it is necessary to first show that the effects of mutations are not affecting the secondary and quaternary structures of the peptides in solution. Therefore in this study, the $\mathrm{N}$-acetylated peptides, shown in Table 1 were studied by $\mathrm{CD}$ and fluorescence spectroscopy. $[7,15,18,31,36]$.

Furthermore, $\mathbf{K}$ (and its derivatives $\mathbf{K}_{\mathbf{K}}$ and $\mathbf{K}_{\mathrm{S}}$ ) and $\mathbf{E}$ were conjugated to DOPE via the flexible spacer $\mathrm{PEG}_{12}$ at the $\mathrm{N}$-terminus for the fusion studies. This design ensures the binding of these lipidated peptides in the membranes of liposomes (vide infra).
Table 1: Information of peptide primary structure. Red letters stand for positive charged amino acid residues, while blue letters stand for negative charged amino acid residues. Underline indicates the 'f' position. Sequence presents from $\mathrm{N}$ terminus to $\mathrm{C}$ terminus. All peptides were acetylated. $\mathrm{Mw}$ - $\mathrm{T}$ is molecular weight in theoretical, while $\mathrm{Mw}$ - $\mathrm{E}$ is molecular weight in experimental.

\begin{tabular}{llll}
\hline Name & $\begin{array}{l}\text { Sequence and residue } \\
\text { charge }\end{array}$ & $\begin{array}{l}\text { Mw-T } \\
\left(\mathrm{g} \mathrm{mol}^{-1}\right)\end{array}$ & $\begin{array}{l}\text { Mw-E } \\
\left(\mathrm{g} \mathrm{mol}^{-1}\right)\end{array}$ \\
\hline Coil-K & Ac-(KIAALKE) $)_{3}-\mathrm{CONH}_{2}$ & 2320.89 & 2320.40 \\
Coil-K $_{\mathrm{S}}$ & AC-(KIAALKS) $_{3}-\mathrm{CONH}_{2}$ & 2194.78 & 2194.41 \\
Coil-K & AC-(KIAALKK) $)_{3}-\mathrm{CONH}_{2}$ & 2318.07 & 2317.59 \\
Coil-E & AC-(EIAALEK) $)_{3}-\mathrm{CONH}_{2}$ & 2323.71 & 2323.34 \\
\hline
\end{tabular}

\subsubsection{Circular Dichroism Spectroscopy: comparison between secondary and quaternary structures.}

In order to investigate peptide structural peculiarities, circular dichroism spectroscopy was performed for $\mathrm{N}$-acetylated peptides. The analysis of the spectra was achieved by the following criteria: 1 ) two negative peaks $\left(\pi-\pi^{*}\right.$ and $n-\pi^{*}$ transitions) with minima at $208 \mathrm{~nm}$ and $222 \mathrm{~nm}$ of equal amplitudes are attributed to $\alpha$-helical conformation, 2) in the case of an ellipticity ratio $[\Theta]_{222} /$ $[\Theta]_{208}$ is $>1$ the $\alpha$-helices are assembled to a coiled coil, 3 ) the presence of coiled coils is confirmed when $[\Theta]_{222} /[\Theta]_{208}$ $=1$ is found in another CD spectrum recorded under coiled coil dissociating conditions (50\% TFE), 4) CD spectra for samples in PBS buffer showing a ratio of $[\theta]_{222} /[\theta]_{208}<1$ are considered to be too complicated for analysis, due to the presence of mixtures, aromatic contributions, etc. It should be noted that for PBS samples containing coiled coils, helical contents calculated from $[\Theta]_{220}$ (Tables 2-3) are overestimated.

The present results showed that all the pure peptides adopt, to a certain degree, $\alpha$-helical structures in PBS buffer, but with exceptions for $\mathbf{E}$ (as expected) and $\mathbf{K}_{\mathbf{S}}$ the latter due to serine's poor propensity to adopt an $\alpha$-helical conformation (Figure 1A and Table 2) [30].

The spectra for the hetero pairs shown in Figure 1B are all characterized by ratios $[\theta]_{222} /[\Theta]_{208}>1$ (Figure 1B, Table 2 ), and can be easily assigned to the presence of coiled-coil structures. Similar spectra are shown for the K-peptide and the $\mathbf{K}$-analogues paired with the E-peptide. The presence of coiled coils is confirmed by the tendency to decrease the $[\theta]_{222} /[\Theta]_{208}$ level under coiled coil-dissociating conditions. Evidently, the charge at the ' $\mathrm{f}$ ' position of $\mathbf{K}$ peptides can be varied without compromising their ability to form coiled coils with $\mathbf{E}$. 

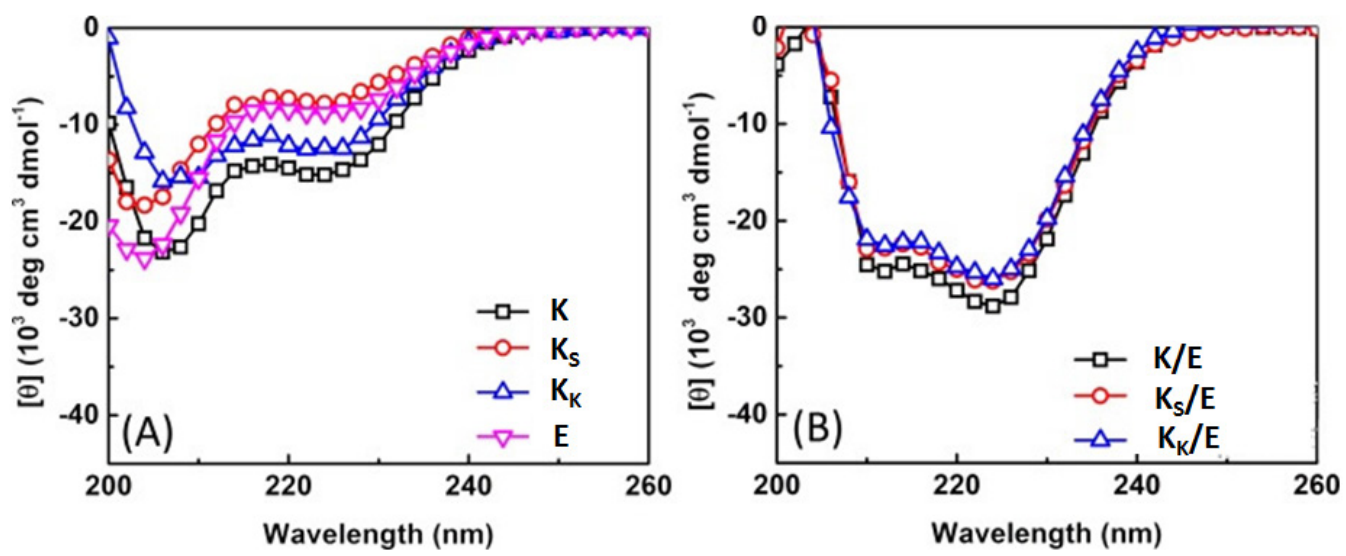

Figure 1: $C D$ spectra of (A) peptides in PBS buffer and (B) an equimolar mixture of the $\mathrm{K}$ variants and $\mathrm{E}$ in PBS buffer. [Total peptide] $=100$ $\mathrm{uM}, \mathrm{pH} 7.4,25^{\circ} \mathrm{C}$.

\subsubsection{Quaternary structures and thermodynamic stabilities of the coiled coil pairs.}

Next, the 1:1 stoichiometry necessary to form a heterodimer was tested for $\mathbf{K} / \mathbf{E}, \mathbf{K}_{\mathrm{S}} / \mathbf{E}$ and $\mathbf{K}_{\mathrm{K}} / \mathbf{E}$ complexes by $\mathrm{CD}$ spectroscopy (Figure 2). A job-plot showing the $[\theta]_{222}$ as a function of the mol fraction of $\mathbf{E}$ peptide yields information on the binding characteristics [38,39]. The job-plot of $\mathbf{K}$ (and its derivatives) and $\mathbf{E}$ mixtures were measured with a total peptide concentration of $200 \mathrm{uM}$ and with variable mol fractions of the two peptides. For all K/E (including derivatives) coiled coil complexes studied, a minimum of $[\theta]_{222}$ was always observed at an equimolar ratio of peptide $\mathbf{K}$ (and derivatives) and $\mathbf{E}$, revealing the formation of a coiled coil complex with a 1:1 stoichiometry (Figure 2A).

At last, the stabilities of the coiled-coils were compared. As the molar ellipticity at $222 \mathrm{~nm}$ is directly proportional to the amount of helical structure and therefore thermal denaturation curves provide information on their folding stabilities[37, 40]. Thus the thermodynamic stability of the $\mathbf{K} / \mathbf{E}$ pairs was determined by measuring the molar ellipticity at $222 \mathrm{~nm}$ wavelength as a function of temperature [22]. All coiled coil pairs showed a smooth cooperative transition from a $\alpha$-helical coiled coil structure to a random coil conformation (Figure 2B). All transitions showed to be fully reversible by lowering the temperature (see supporting information Figure S6). Temperature-dependent CD measurements showed that all the peptide complexes used in this study have an identical two-state transition denaturation process, dissociating from a coiled coil to random coils.

The binding parameters of the studied coiled coil heterodimers are summarized in Table 4. Either the similarity in binding stoichiometry or the resemblance
Table 2: CD spectroscopic data of the acetylated peptides in PBS buffer.

\begin{tabular}{|c|c|c|c|c|c|c|c|c|}
\hline \multirow[t]{2}{*}{ Name } & \multicolumn{2}{|c|}{$[\theta]_{222}\left(\times 10^{3}\right)$} & \multicolumn{2}{|c|}{$[\theta]_{208}\left(\times 10^{3}\right)$} & \multicolumn{2}{|c|}{$[\theta]_{222} /[\theta]_{208}$} & \multicolumn{2}{|c|}{$\% \alpha$-helix ${ }^{a}$} \\
\hline & PBS & $50 \%$ & PBS & $50 \%$ & PBS & $50 \%$ & PBS & $50 \%$ \\
\hline & & TFE & & TFE & & TFE & & TFE" \\
\hline K & -15.2 & -20.2 & -22.5 & -21.9 & 0.67 & 0.92 & 49 & 65 \\
\hline $\mathrm{K}_{\mathrm{s}}$ & -7.6 & -10.3 & -14.7 & -11.6 & 0.52 & 0.88 & 24 & 33 \\
\hline $\mathrm{K}_{\mathrm{K}}$ & -12.5 & -22.1 & -15.4 & -25.2 & 0.81 & 0.88 & 40 & 70 \\
\hline $\mathrm{E}$ & -8.8 & -13.1 & -19.1 & -13.1 & 0.46 & 1.00 & 28 & 42 \\
\hline
\end{tabular}

a The percentage $\alpha$-helicity is the ratio of the observed $[\theta]_{222}$ to the predicted $[\theta]_{222}$ for an $\alpha$-helical peptide of $\mathrm{n}$ residues times 100 . The predicted $\alpha$-helicity is calculated from $[\theta]_{222}=-40000 \times(1-4.6 / \mathrm{n})$ [37]. PBS buffer $\mathrm{pH}=7.4$.

in dissociation constant of all coiled coils show that replacing the negatively charged glutamate with a neutral serine or a cationic lysine on the ' $\mathrm{f}$ ' position in peptide $\mathbf{K}$ does not influence the ability to form coiled coils, while the changes in DG are minor.

\subsubsection{Fluorescence spectroscopy: comparison of the quaternary structures}

The relative peptide orientation within a coiled coil motif (i.e. parallel vs antiparallel) was investigated by fluorescence spectroscopy. For this, $\mathbf{K}\left(\mathbf{K}_{\mathrm{S}}\right.$ and $\left.\mathbf{K}_{\mathbf{K}}\right)$ were labelled with a tryptophan $(\mathrm{W})$ at the $\mathrm{C}$-terminus, yielding $\mathbf{K}^{\prime}\left(\mathbf{K}_{\mathbf{S}}\right.$ or $\mathbf{K}_{\mathbf{K}}$, see Table 5 and supplemental information Figure S2). In addition, Tyrosine (Y) was added to the C-terminus of E, giving E'. Glycine $(\mathrm{G})$ was added in between aromatic amino acid ( $\mathrm{W}$ and $\mathrm{Y}$ ) and the original 

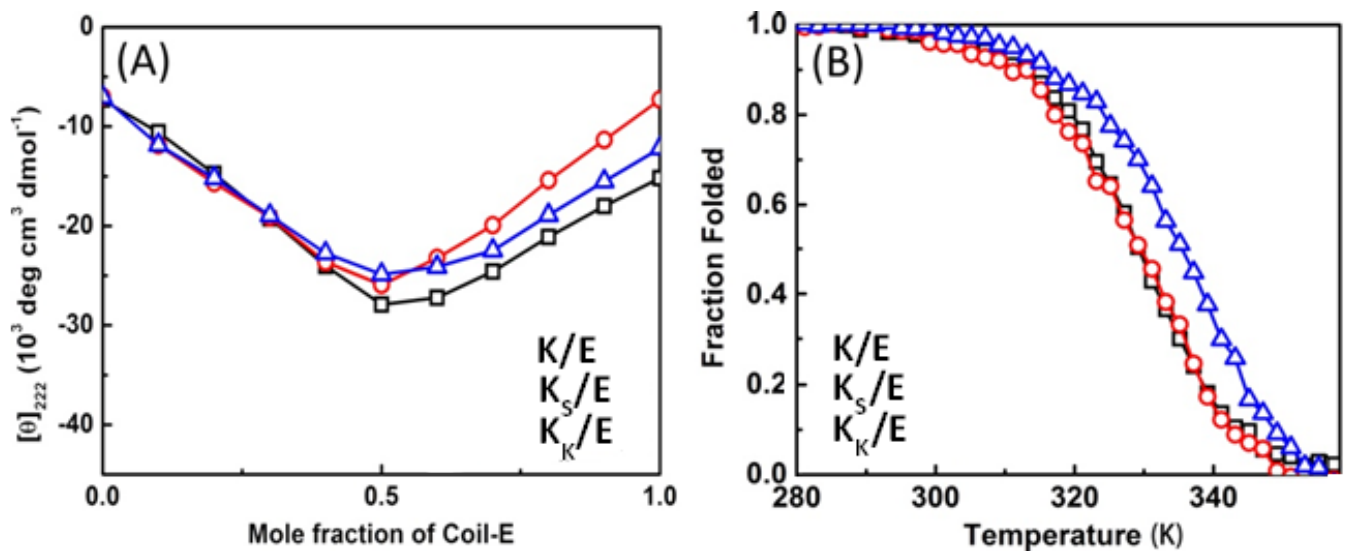

Figure 2: A) Mean residue molar ellipticities at $222 \mathrm{~nm}$ wavelength for mixtures of the $\mathrm{K}$ (or its derivatives) and $\mathrm{E}$ peptides as a function of the mol fraction of the E peptide. [Total peptide] $=100 \mathrm{uM}, 25^{\circ} \mathrm{C}, 2 \mathrm{~mm}$ quartz cuvette. (B) Thermal unfolding curves of coiled coils in PBS buffer $(\mathrm{pH}=7.4)$ with increasing temperature from $6^{\circ} \mathrm{C}(279 \mathrm{~K})$ till $86^{\circ} \mathrm{C}(359 \mathrm{~K}) . \mathrm{A} 1 \mathrm{~cm}$ quartz cuvette with stirring bar at $900 \mathrm{rpm}$ was used. [Total peptide] $=40 \mathrm{uM}, \mathrm{PBS}, \mathrm{pH}=7.4$.

Table 3: CD spectroscopic data of the acetylated peptide K/E complex and derivatives in PBS buffer.

\begin{tabular}{|c|c|c|c|c|c|c|c|c|c|}
\hline \multirow[t]{2}{*}{ Complex ${ }^{a}$} & \multicolumn{2}{|c|}{$[\theta]_{222}\left(\times 10^{3}\right)$} & \multicolumn{2}{|c|}{$[\theta]_{208}\left(\times 10^{3}\right)$} & \multicolumn{2}{|c|}{$[\theta]_{222} /[\theta]_{208}$} & \multicolumn{2}{|c|}{$\% \alpha$-helix } & \multirow[t]{2}{*}{$\mathrm{CC}^{\mathrm{b}}$} \\
\hline & PBS & $50 \%$ TFE & PBS & $50 \%$ TFE & PBS & $50 \%$ TFE & PBS & $50 \%$ TFE & \\
\hline $\mathrm{K} / \mathrm{E}$ & -28.3 & -23.0 & -15.9 & -27.4 & 1 & 0.84 & 91 & 74 & + \\
\hline$K_{s} / E$ & -26.1 & -18.6 & -16.0 & -23.6 & 1 & 0.79 & 84 & 60 & + \\
\hline $\mathrm{K}_{\mathrm{K}} / \mathrm{E}$ & -25.3 & -22.8 & -17.6 & -28.4 & 1 & 0.84 & 81 & 73 & + \\
\hline
\end{tabular}

a Complex refers to mixtures of the stated compounds with equimolar concentrations. ${ }^{b} \mathrm{CC}$ means coiled coil, and + signifies a significant decrease in the $[\theta]_{222} /[\Theta]_{208}$ ratio from benign to $50 \%$ TFE in PBS, indicative of the folded coiled-coil structure in PBS .

Table 4: Binding constants of coiled coils from CD spectroscopy.

\begin{tabular}{lllll}
\hline Coiled-coil & $\left.\mathrm{T}_{\mathrm{m}}{ }^{\circ} \mathrm{C}\right)^{\mathrm{a}}$ & Stoichiometry & $\begin{array}{l}\Delta \mathrm{G}_{\mathrm{u}} \\
\left(\mathrm{kcal} \mathrm{mol}^{-1}\right)^{\mathrm{b}}\end{array}$ & $\mathrm{K}_{\mathrm{d}}\left({ }^{*} 10^{-8} \mathbf{M}\right)^{\mathrm{c}}$ \\
\hline $\mathrm{K} / \mathrm{E}$ & 56 & $1: 1$ & 10 & 6.7 \\
$\mathrm{~K}_{\mathrm{s}} / \mathrm{E}$ & 56 & $1: 1$ & 9.5 & 7.4 \\
$\mathrm{~K}_{\mathrm{K}} / \mathrm{E}$ & 60 & $1: 1$ & 9.9 & 5.4 \\
\hline
\end{tabular}

${ }^{\mathrm{a}} \mathrm{T}_{\mathrm{m}}=$ melting temperature, at which half of the peptide is in the unfolded form. ${ }^{\mathrm{b}} \Delta \mathrm{G}_{\mathrm{u}}=$ Gibbs free energy of unfolding at $25^{\circ} \mathrm{C} .{ }^{\mathrm{c}}$ $\mathrm{K}_{\mathrm{d}}=$ dissociation constant at $25^{\circ} \mathrm{C}$.

peptide sequence to avoid significant structure.[29] The relative orientation of the two peptides within a coiled coil complex was confirmed by a fluorescence resonance energy transfer (FRET) between the donor Y on E', and the acceptor (W) on K' (including its derivatives). Both fluorophores are at the $\mathrm{C}$-termini of the peptides, and the Förster distance $\left(\mathrm{R}_{0} \approx 1 \mathrm{~nm}\right)$ is shorter than the length of the peptides in a $\alpha$-helical fashion $(\sim 3-4 \mathrm{~nm})$ (see supplemental information Figure S5-1), which stringently ensures that FRET can only occur when the peptides are assembled with a parallel orientation, not when an antiparallel orientation is adopted [29,41].

Figure 3 shows the emission spectra (excitation at $275 \mathrm{~nm}$ ) of peptides $\mathbf{K}^{\prime}$ (and its derivatives) and $\mathbf{E}$ ', K'/E' (including its derivatives) in PBS and in 1:1 PBS: TFE solution. An equimolar mixture of Coil-K' and Coil-E' results in an increased fluorescence signal of acceptor $\mathrm{W}$ and a decreased fluorescence signal of donor $\mathrm{Y}$ due to fluorescence resonance energy transfer (FRET), thus indicating a parallel coiled coil orientation for $\mathbf{K}^{\prime} / \mathbf{E}^{\prime}$ (Figure $3 \mathrm{~A}$ ). In the presence of $50 \% \mathrm{TFE}$, the energy transfer is lost due to the dissociation of coiled coil complex. Consistently, $\mathbf{K}_{\mathrm{s}}$ /E and $\mathbf{K}_{\mathrm{K}}$ '/E also showed a parallel coiled coil orientation (Figure 3B, C).

Both $\mathrm{CD}$ and fluorescence measurements showed that replacing the negatively charged glutamate residue at the ' $\mathrm{f}$ ' position with either the positively charged lysine or non-charged serine on position ' $\mathrm{f}$ ' in $\mathbf{K}$ did not significantly alter the peptide ability to form a coiled coil. Hence, we consider the electrostatic interaction 

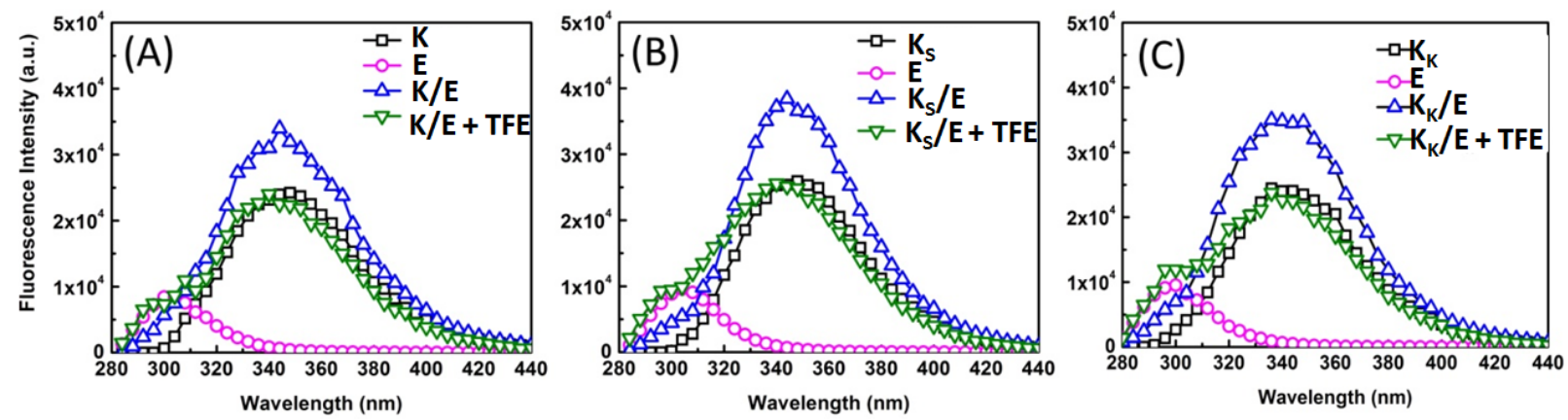

Figure 3: Fluorescence emission spectra (extension at $275 \mathrm{~nm}$ ) of fluorescent labeled peptides $50 \mathrm{uM}$ in either pH=7.4 PBS buffer or 1:1 TFE/ PBS solution on $25^{\circ} \mathrm{C}$. For instance, (A) shows fluorescence signal of $\mathrm{K}^{\prime}$ (black), E'(purple) respectively in PBS buffer, and the signal when they are 1:1 forming into coiled coil complexes (blue). Green signal indicates coiled coil disassociation via 50\% TFE addition. (B) and (C) shows $\mathrm{K}_{\mathrm{s}}^{\prime}$ and $\mathrm{K}_{\mathrm{K}}^{\prime}$ interaction with $\mathbf{E}^{\prime}$ respectively.

Table 5: Fluorescent labeled peptide primary structure.

\begin{tabular}{llll}
\hline Name & Sequence $^{\text {a }}$ & $\begin{array}{l}\text { Mw-T } \\
\text { (g mol-1) }\end{array}$ & $\begin{array}{l}\text { Mw-E } \\
\text { (g mol-1) }\end{array}$ \\
\hline K' $^{\prime}$ & $\begin{array}{l}\text { Ac-(KIAALKE)3-GW- } \\
\text { CONH2 }\end{array}$ & 2563.6 & 2564.15 \\
$\mathbf{K}_{\mathrm{s}}{ }^{\prime}$ & $\begin{array}{l}\text { Ac-(KIAALKS)3-GW- } \\
\text { CONH2 }\end{array}$ & 2437.59 & 2438.04 \\
$\mathbf{K}_{\mathrm{K}}{ }^{\prime}$ & $\begin{array}{l}\text { Ac-(KIAALKK)3-GW- } \\
\text { CONH2 }\end{array}$ & 2560.59 & 2561.33 \\
$\mathbf{E}^{\prime}$ & $\begin{array}{l}\text { AC-(EIAALEK)3-GY- } \\
\text { CONH2 }\end{array}$ & 2543.61 & 2543.94 \\
\hline
\end{tabular}

${ }^{\text {a }}$ All the peptides primary structures present from $\mathrm{N}$ to $\mathrm{C}$ terminus.

Table 6: Lipopeptides used in this study.

\begin{tabular}{lllll}
\hline Name & $\begin{array}{l}\text { MW-T } \\
\text { (g mol-1) }\end{array}$ & $\begin{array}{l}\text { MW-E } \\
(\mathbf{g} \text { mol-1) }\end{array}$ & Yield & Purity $^{\text {a }}$ \\
\hline LPK & 3704.10 & 3704.01 & $60 \%$ & $>95 \%$ \\
LPK $_{\mathrm{S}}$ & 3577.88 & 3577.80 & $65 \%$ & $>95 \%$ \\
LPK $_{\mathrm{K}}$ & 3701.19 & 3701.19 & $50 \%$ & $>95 \%$ \\
LPE & 3706.54 & 3706.54 & $63 \%$ & $>95 \%$ \\
\hline
\end{tabular}

as the only difference in the following liposome fusion studies.

\subsection{Lipopeptide mediated liposome fusion study}

\subsubsection{Lipopeptide synthesis}

The lipopeptides were synthesized as previously reported. [15] The lipopeptides were cleavaged from the resin as precipitation by using a cocktail of TFA, DCM, phenol and TIS (70:22.5:5:2.5\% v/v), and further purified by high performance liquid chromatography (HPLC) using a C18 reversed-phase column (See Table 6 and supplemental information Figures S3) for quality of lipopeptides).

\subsubsection{CD spectroscopy of lipopeptides in liposomes}

The peptides (including analogues) DOPE-PEG tethered to liposomal membranes were studied at a concentration of $1 \mathrm{~mol} \%$. The spectra are shown in Figure 4. Compared to the spectra shown above for the acetylated peptides in PBS solution, the spectra of the lipopeptides should be analysed with even more caution because of the unknown effects of peptide-membrane interactions on the shape of the spectra as well as the broadening of thelines due to light scattering due to the presence of peptides tethered both at the inner and outer leaflets of vesicular membranes with the size of $200 \mathrm{~nm}$, that may lead to different interference at low wave lengths of the CD spectrum.

This might be the reason for the observation of too small line widths and shifts of the minima around $208 \mathrm{~nm}$ shown in the spectra of $\mathbf{L P K}, \mathbf{L P K}_{\mathrm{S}}$ and $\mathbf{L P K} \mathbf{K}_{\mathrm{K}}$.

The spectra of LPK/LPE pairs shown in Figure 4B are more informative. Compared to the observations for peptides in solution the spectra of membrane bound LPK/ LPE pairs shows a small red shift for the minimum at 222 $\mathrm{nm}$ of $2 \mathrm{~nm}$. This might be due to a different dielectric of the membrane environment relative to that of acetylated $\mathbf{E} / \mathbf{K}$ peptides in aqueous buffered solutions [42-44]. But this red shift is not shown for the analogue $\mathbf{K}_{\mathrm{S}}$ and $\mathbf{K}_{\mathrm{K}}$ peptides probably due to slightly different environments. Furthermore, the spectrum of LPK/LPE in liposomes revealed a $[\Theta]_{225} /[\Theta]_{208}$ ratio larger than 1 , indicating the 

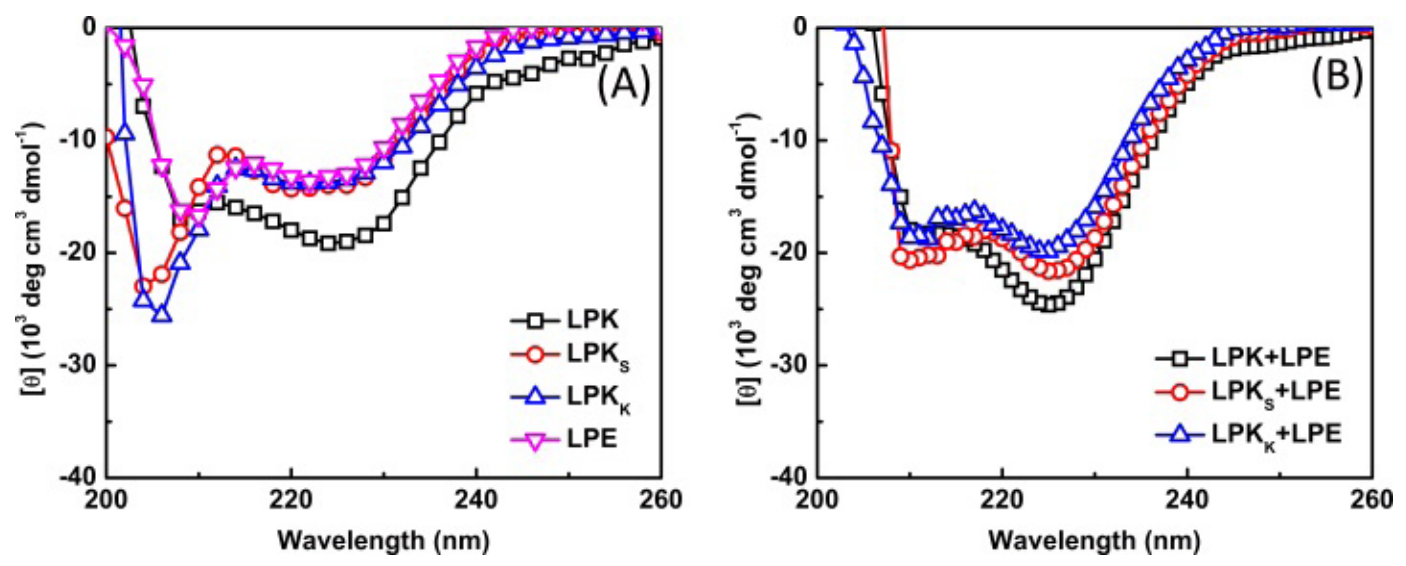

Figure 4: (A) Circular dichroism spectra of 1 mol\% lipopeptide on liposomal membranes. (B) Equimolar mixture of LPK (and its derivatives) and LPE on liposomes. [Lipids] $=0.5 \mathrm{mM}$, PBS buffer, $\mathrm{pH}=7.4,25^{\circ} \mathrm{C}$.

presence of some coiled coils. In contrast, the other spectra of the analogue pairs $\left(\mathbf{L P K}_{\mathrm{S}} / \mathbf{L P E}, \mathbf{L P K} \mathrm{K}_{\mathrm{K}} / \mathbf{L P E}\right)$ showed a $[\Theta]_{225} /[\Theta]_{208}$ ratio almost equal to 1 , implying that coiled-coil formation was significantly suppressed $[22,45]$. This circular dichroism study indicates that changes of the charge at the ' $\mathrm{f}$ ' position in $\mathbf{K}$ influences the peptide behaviour at the liposomal membrane, possibly indicating another role of individual $\mathbf{K}$ and $\mathbf{E}$ peptides during the fusion.

\subsection{Liposome fusion studies}

\subsubsection{Dynamic light scattering}

The effect of charge at the ' $\mathrm{f}$ ' position of $\mathbf{K}$ on the rate of membrane fusion was studied with dynamic light scattering (DLS) and lipid and content mixing assays as well. DLS data shown in supplemental information Figure S7 indicate a 7 fold hydrodynamic diameter increase observed at 30 minutes after mixing LPK/ LPE decorated liposomes. Within this time period we did not observe any difference for native and analogue membrane tethered peptides. After 30 minutes the increase in the hydrodynamic diameter deviates. However, at these diameters DLS becomes less reliable and therefore it is difficult to draw any conclusions on the size increase in this time range. Furthermore, it is important to note that DLS cannot distinguish liposome content mixing events. It can be concluded that the studied lipopeptide pairs are able to at least induce docking behaviour of liposomes.

\subsubsection{Lipid mixing experiment}

The rate of lipid mixing was determined by a standard FRET assay. LPK molecules bound to fluorophore labelled liposomes (denoted as $\mathbf{L P K}-\mathbf{L}_{\mathrm{F}}$ ) contained both the donor dye nitrobenzofuran (NBD) and the acceptor dye lissamine rhodamine (LR) attached to the membrane, while LPE modified liposomes were not labelled with fluorescent dyes. These liposomes were stable with time and did not show any membrane fusion for at least $60 \mathrm{~min}$ (See supporting information Figure S9-S10). Upon equimolar mixing of $\mathbf{L P K}-\mathbf{L}_{\mathbf{F}}$ liposomes with LPE liposomes, an immediate increase in the NBD emission was observed as a result of a decreased FRET efficiency due to the increase in the average distance between NBD and LR. This is due to lipid mixing between $\mathbf{L P K}-\mathbf{L}_{\mathrm{F}}$ - and $\mathbf{L P E}$ liposomes. Figure $5 \mathrm{~A}$ shows that in all three experiments full lipid mixing (i.e. 100\%) was achieved within $60 \mathrm{~min}$. However, fusion between $\mathbf{L P K}_{\mathrm{K}}-\mathbf{L}_{\mathrm{F}}$ - and $\mathbf{L P E}$ liposomes showed the highest initial lipid mixing rate. Also fusion between $\mathbf{L P K} \mathbf{S}_{\mathrm{s}}-\mathbf{L}_{\mathrm{F}}$ with LPE liposomes resulted in a higher lipid mixing rate as compared to the fusion induced by the original LPK and LPE-peptides. Thus, varying the charge in $\mathbf{K}$ at the ' $\mathrm{f}$ ' position resulted in differences in the initial lipid mixing rate, albeit these became smaller at longer time scales.

\subsubsection{Liposome content mixing experiment}

Next, a liposome fusion content mixing assay was performed, which revealed a more pronounced difference between the three pairs of membrane tethered peptides (i.e. LPK/LPE, LPK $_{\mathrm{S}} / \mathbf{L P E}, \mathbf{L P K}_{\mathrm{K}} / \mathbf{L P E}$ ). In this experiment, LPE modified liposomes were loaded with sulphorhodamine 

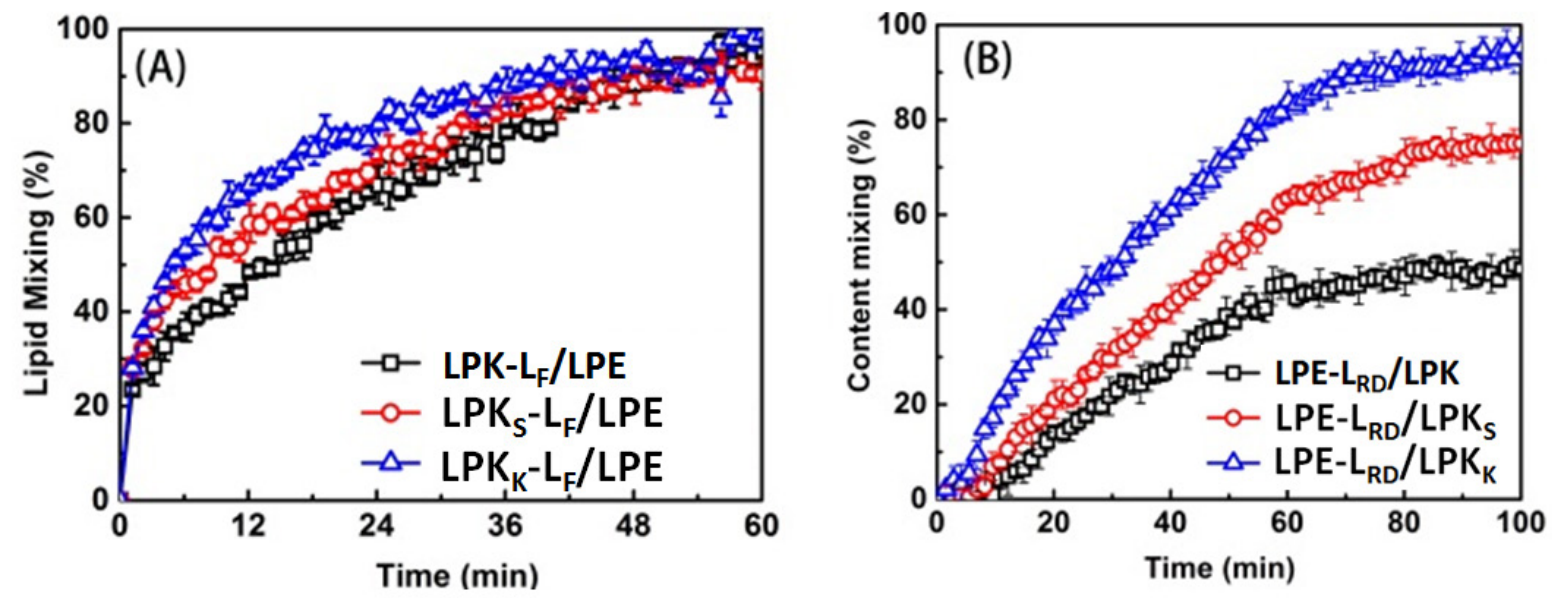

Figure 5: (A) Fluorescence traces showing lipid mixing between fluorescence (NBD/LR) labeled LPK- $\mathrm{L}_{\mathrm{F}}$ (and derivatives) liposomes with non-fluorescence labeled LPE liposomes. (B) Content mixing between non-fluorescent LPK liposomes with sulforhodamine labelled (20 $\mathrm{mM}$ ) LPE-L liposomes. Liposome concentration is $0.1 \mathrm{mM}$ with $1 \%$ peptide decoration. The bars show the standard deviations ( $\sigma$ ). See Figure S9-S10 for the control experiments of lipid mixing and content mixing fluorescence spectra. All the measurements were performed in PBS, $\mathrm{pH} 7.4$, at $25^{\circ} \mathrm{C}$.

B at a self-quenching concentration of $20 \mathrm{mM}$, yielding LPE- $\mathbf{L}_{\mathrm{RD}}$ liposomes, while LPK (including its derivatives) modified liposomes did not contain dyes in the aqueous interior. Upon mixing of the liposomes, fusion resulted in the transfer of content transfer with a concomitant dilution of the rhodamine dye, thereby alleviating the self-quenching and a subsequent increase in fluorescence intensity (Figure 5B).

Remarkably, significant differences in content mixing were observed as a function of the differently charged peptides used. Within 100 min, fusion between $\mathbf{L P E} \mathbf{L}_{\mathrm{RD}}$ liposomes and $\mathbf{L P K}_{\mathbf{K}}$-liposomes yielded 95\% of content mixing, which is significantly higher as compared to the original peptide design (i.e. LPK/LPE modified liposomes has $45 \%$ content mixing) Using $\mathbf{L P K}_{\mathrm{S}} / \mathbf{L P E}-\mathbf{L}_{\mathrm{RD}}$ modified liposomes with a neutral charge at the ' $\mathrm{f}$ ' position also gave an increased fusion efficiency, but less pronounced when compared to the LPKk/LPE-LRD liposomes. (See supporting information Figures S9 and S10 for DLS data.). Control spectra showed the absence of any leakage of the vesicles during fusion (supplemental information Figures S9 and S10.

\section{Discussion}

Both $\mathrm{CD}$ and fluorescence measurements showed that replacing the negatively charged glutamate by either neutral serine or cationic lysine residues does not significantly alter the peptide ability to form an $\mathbf{E} / \mathbf{K}$ coiled coils. But lipid mixing and content mixing assays showed more efficient liposome-liposome fusion resulting in almost quantitative content mixing for the lysine mutated analogue $\left(\mathbf{L P K}_{\mathrm{K}}\right)$ in conjunction with $\mathbf{L P E}$. The important role of the lysine residues at the $\alpha$-helical ' $f$ ' positions, replacing the anionic glutamates, on the efficiency of fusion was a big surprise, since in the original design of fusion promoting peptides the negative charges were assumed to be important for coiled coil formation by decreasing the total charge and to increase the solubility of the peptides [22]. In the present study, however, we did not encountered any problems with the solubility of coiled-coil complexes and free peptides.

It is generally anticipated that the first step in membrane fusion, triggered by DOPE-anchored peptides, is a vesicle docking due to the formation of one or more $\mathbf{E} / \mathbf{K}$ coiled-coil complexes to bring the two vesicles in close proximity. Previously reported MD experiments, however, showed that monomeric $\mathbf{K}$ molecules binds to the membrane while $\mathbf{E}$ molecules remain water exposed. The positive curvature of the membrane near the peptide binding site of the amphipathic helical K-peptides would lead to a further reduction of the intermembrane distance and promotes the destabilization of the membrane by a lack of cholesterol. These local membrane perturbations would also initiate the protrusion of lipid acyl chains. However, little is known about the role of LPE at the key step to further destabilize the opposing membranes to enable fusing and finally leading to mixing the contents of the fused liposomes. In more recent work, peptide $\mathbf{E}$ 
was proposed to act as an intermediate handle to form an intermediate coiled-coil by reducing the undesired membrane interaction of the $\mathbf{K}$ peptide to further decrease the distance of the two membranes at the critical prefusion state [49].

In the present study we showed that knowledge about electrostatic interactions between coiled-coil forming peptides is essential for a better understanding of fusion. Remarkably, the $\mathbf{K}_{\mathrm{K}}$ analogue was found almost doubling the efficiency of fusion, probably due to the improved interaction between the membrane tethered $\mathbf{K}_{\mathrm{K}}$ and $\mathbf{E}$ molecules leading to halving the average distance between the two different membranes. Although more spectroscopic investigations are needed, the present results represent new insight about the important role of electrostatic interactions between fusogenic peptides and lipids.

\section{Conclusion}

Membrane fusion, mediated by membrane tethered lipopeptides LPK/LPE, was investigated by mutating the negatively charged glutamate at position ' $\mathrm{f}$ ' of the helical $\mathbf{K}$-molecule to the non-charged amino acid serine and the positively charged lysine, respectively. It was shown that the ability to form a coiled-coil was not influenced by these mutations. However, after mixing the $\mathbf{L P K}_{\mathrm{K}}$ decorated liposomes with LPE decorated ones, the system triggers significant improvement of lipid mixing and almost reaches $100 \%$ of content mixing, thereby doubling the efficiency of fusion in comparison with the original LPK/LPE system. The $\mathbf{L P K}_{s} / \mathbf{L P E}$ system showed a rather weaker fusion than $\mathbf{L P K}_{\mathrm{K}} / \mathbf{L P E}$, but still exhibits more fusion than the native system. The present results support recently reported MD simulation data about the topology of a membrane bound amphipathic K-helix, thereby also confirming the earlier proposed snorkelling mechanism for the lysine residues located at the 'e' and ' $\mathrm{g}$ ' positions of the helical wheel and the solvent exposed glutamates at the ' $\mathrm{f}$ '-positions. The latter finding implicates the anionic character of the membrane bound $\mathbf{K}$-peptide that would be otherwise cationic, seriously hampering coiled coil formation with anionic E-peptide. Thus, serious evidences reported here show that electrostatic molecular recognition between membrane bound cationic $\mathbf{K}_{\mathbf{K}}$ and the handle-like floating $\mathbf{E}$ is one of the most important key factors significantly improving the efficiency of fusion. Finally, the finding of the extremely active two-component peptide system may help to develop a better full fusion drug delivery system.
Acknowledgements: We thank Prof. Dr. Alexander Kros and Dr. Jan Raap for discussion and language polishing. We thank Dr. Kristyna Pluhackova (University of ErlangenNürnberg, Germany) for the stimulating discussions and for providing the MD picture of the membrane bound K-peptide. We acknowledges the support of the European Research Council (ERC) via an ERC starting grant (240394); National Natural Science Foundation of China (81871358); China postdoctoral fund (2018M640807); Ministry of Science and Technology of China (2016YFC0104707); Natural Science Foundation of Guangdong Province, China (2018A0303130228); the Science and Technology Planning Project of Shenzhen Municipality, China (JCYJ20160429090753103) and Joint Project of Peking University- Griffth University No. 036 Research Internal.

Conflict of interest: Authors declare no conflict of interest.

\section{References}

[1] Gerst J.E., SNAREs and SNARE regulators in membrane fusion and exocytosis, Cell. Mol. Life Sci., 1999, 55 707-734.

[2] Rothman J.E., The Principle of Membrane Fusion in the Cell (Nobel Lecture), Angew. Chem. Int. Ed., 2014, 53, 12676-12694.

[3] D’Agostino M., Risselada H.J., Luerick A., Ungermann C., Mayer A., A tethering complex drives the terminal stage of SNAREdependent membrane fusion, Nature, 2017, 551, 634-638.

[4] Mellman I., Emr S.D., A Nobel Prize for membrane traffic: Vesicles find their journey's end, J. Cell Biol., 2013, 203, 559561.

[5] Wickner W., Schekman R., Membrane fusion, Nat. Struct. Mol. Biol., 2008, 15, 658-664.

[6] Jahn R., Lang T., Sudhof T.C., Membrane fusion, Cell, 2003, 112, 519-533.

[7] Hu C., Ahmed M., Melia T.J., Sollner T.H., Mayer T., Rothman J.E., Fusion of cells by flipped SNAREs, Science, 2003, 300, 1745-1749.

[8] Sudhof T.C., Rothman J.E., Membrane Fusion: Grappling with SNARE and SM Proteins, Science, 2009, 323, 474-477.

[9] Fasshauer D., Antonin W., Subramaniam V., Jahn R., SNARE assembly and disassembly exhibit a pronounced hysteresis, Nat. Struct. Biol., 2002, 9, 144-151.

[10] Tomatsu I., Marsden H.R., Rabe M., Versluis F., Zheng T., Zope H., et al., Influence of pegylation on peptide-mediated liposome fusion, J. Mater. Chem., 2011, 21, 18927-18933.

[11] Blumenthal R., Clague M.J., Durell S.R., Epand R.M., Membrane fusion, Chem. Rev., 2003, 103, 53-69.

[12] Marsden H.R., Elbers N.A., Bomans P.H.H., Sommerdijk N.A.J.M., Kros A., A Reduced SNARE Model for Membrane Fusion, Angew. Chem. Int. Ed., 2009, 48, 2330-2333.

[13] Chen X.C., Arac D., Wang T.M., Gilpin C.J., Zimmerberg J., Rizo J., SNARE-mediated lipid mixing depends on the physical state of the vesicles, Biophys. J., 2006, 90, 2062-2074. 
[14] Marsden H.R., Elbers N.A., Bomans P.H.H., Sommerdijk N., Kros A., A Reduced SNARE Model for Membrane Fusion, Angew. Chem. Int. Ed., 2009, 48, 2330-2333.

[15] Marsden H.R., Korobko A.V., Zheng T.T., Voskuhl J., Kros A., Controlled liposome fusion mediated by SNARE protein mimics, Biomater. Sci., 2013, 1, 1046-1054.

[16] Versluis F., Dominguez J., Voskuhl J., Kros A., Coiled-coil driven membrane fusion: zipper-like vs. non-zipper-like peptide orientation, Faraday Discuss., 2013, 166, 349-359.

[17] Versluis F., Voskuhl J., Vos J., Friedrich H., Ravoo B.J., Bomans P.H.H., et al., Coiled coil driven membrane fusion between cyclodextrin vesicles and liposomes, Soft Matter, 2014, 10 9746-9751.

[18] Zheng T.T., Bulacu M., Daudey G., Versluis F., Voskuhl J., Martelli G., et al., A non-zipper-like tetrameric coiled coil promotes membrane fusion, RSC Adv., 2016, 6, 7990-7998.

[19] Zheng T.T., Boyle A., Marsden H.R., Valdink D., Martelli G., Raap J., et al., Probing coiled-coil assembly by paramagnetic NMR spectroscopy, Org. Biomol. Chem., 2015, 13, 1159-1168.

[20] Kong L., Askes S.H.C., Bonnet S., Kros A., Campbell F., Temporal Control of Membrane Fusion through Photolabile PEGylation of Liposome Membranes, Angew. Chem. Int. Ed., 2016, 55, 1396-1400.

[21] Mora N.L., Bahreman A., Valkenier H., Li H.Y., Sharp T.H., Sheppard D.N., et al., Targeted anion transporter delivery by coiled-coil driven membrane fusion, Chem. Sci., 2016, 7, 1768 1772.

[22] Litowski J.R., Hodges R.S., Designing heterodimeric twostranded alpha-helical coiled-coils - Effects of hydrophobicity and alpha-helical propensity on protein folding, stability, and specificity, J. Biol. Chem., 2002, 277, 37272-37279.

[23] Kumar P., van Son M., Zheng T., Valdink D., Raap J., Kros A., et al., Coiled-coil formation of the membrane-fusion K/E peptides viewed by electron paramagnetic resonance, PLoS One, 2018, https://journals.plos.org/plosone/article?id=10.1371/journal. pone.0191197.

[24] Lyu P.C., Liff M.I., Marky L.A., Kallenbach N.R., Side-chain contributions to the stability of alpha-helical structure in peptides, Science, 1990, 250, 669-673.

[25] Marsden H.R., Korobko A.V., Zheng T., Voskuhl J., Kros A., Controlled liposome fusion mediated by SNARE protein mimics, Biomater. Sci., 2013, 1, 1046-1054.

[26] Rabe M., Aisenbrey C., Pluhackova K., de Wert V., Boyle A.L., Bruggeman D.F., et al., A Coiled-Coil Peptide Shaping Lipid Bilayers upon Fusion, Biophys. J., 2016, 111, 2162-2175.

[27] Rabe M., Zope H.R., Kros A., Interplay between Lipid Interaction and Homo-coiling of Membrane-Tethered Coiled-Coil Peptides, Langmuir, 2015, 31, 9953-9964.

[28] Daudey G.A., Zope H.R., Voskuhl J., Kros A., Boyle A.L., Membrane-Fusogen Distance Is Critical for Efficient CoiledCoil-Peptide-Mediated Liposome Fusion, Langmuir, 2017, 33 , 12443-12452.

[29] Zheng T., Boyle A., Marsden H.R., Valdink D., Martelli G., Raap J., et al., Probing coiled-coil assembly by paramagnetic NMR spectroscopy, Org. Biomol. Chem., 2015, 13, 1159-1168.

[30] Pace C.N., Scholtz J.M., A helix propensity scale based on experimental studies of peptides and proteins, Biophys. J., $1998,75,422-427$
[31] Robson-Marsden H., Elbers N.A., Bomans P.H.H., Sommerdijk N.A.J.M., Kros A., A Reduced SNARE Model for Membrane Fusion, Angew. Chem. Int. Ed., 2009, 48, 2330-2333.

[32] Kelly S.M., Price N.C., The application of circular dichroism to studies of protein folding and unfolding, Biochim. Biophys. Acta, Protein Struct. Mol. Enzymol., 1997, 1338, 161-185.

[33] Kelly S.M., Jess T.J., Price N.C., How to study proteins by circular dichroism, Biochim. Biophys. Acta, Proteins Proteomics, 2005, 1751, 119-139.

[34] Lavigne P., Crump M.P., Gagne S.M., Hodges R.S., Kay C.M., Sykes B.D., Insights into the mechanism of heterodimerization from the H-1-NMR solution structure of the c-Myc-Max heterodimeric leucine zipper, J. Mol. Biol., 1998, 281, 165-181.

[35] Lavigne P., Kondejewski L.H., Houston M.E., Sonnichsen F.D., Lix B., Sykes B.D., et al., Preferential heterodimeric parallel coiled-coil formation by synthetic max and C-MYC leucine zippers- a description of putative electrostatic interactions responsible for the specificity of heterodimerization, J. Mol. Biol., 1995, 254, 505-520.

[36] Marsden H.R., Zheng T.T., Kros A., Controlled liposome fusion mediated by SNARE protein mimics, Abstr. Pap. Am. Chem. S., 2013, 245.

[37] Chen Y.H., Yang J.T., Chau K.H., Determination of helix and betaform of proteins in aqueous-solution by circular-dichroism, Biochemistry, 1974, 13, 3350-3359.

[38] Huang C.Y., Determination of binding stoichiometry by the continuous variation method - the job plot, Methods Enzymol. 1982, 87, 509-525.

[39] Hill Z.D., Maccarthy P., Novel-approach to job method - an undergraduate experiment, J. Chem. Educ., 1986, 63, 162-167.

[40] Boice J.A., Dieckmann G.R., DeGrado W.F., Fairman R., Thermodynamic analysis of a designed three-stranded coiled coil, Biochemistry, 1996, 35, 14480-14485.

[41] Zheng T., Bulacu M., Daudey G., Versluis F., Voskuhl J., Martelli G., et al., A non-zipper-like tetrameric coiled coil promotes membrane fusion, RSC Adv., 2016, 6, 7990-7998.

[42] Park K., Perczel A., Fasman G.D., Differentiation between transmembrane helices and peripheral helices by the deconvolution of circular-dichroism spectra of membraneproteins, Protein Sci., 1992, 1, 1032-1049.

[43] Cascio M., Wallace B.A., Red- and blue-shifting in the circular dichroism spectra of polypeptides due to dipole effects, Protein Pept. Lett., 1994, 1, 136-140.

[44] Wallace B.A., Lees J.G., Orry A.J.W., Lobley A., Janes R.W., Analyses of circular dichroism spectra of membrane proteins, Protein Sci., 2003, 12 875-884.

[45] Zhou N.E., Kay C.M., Hodges R.S., Synthetic model proteins - the relative contribution of leucine residues at the nonequivalent positions of the 3-4 hydrophobic repeat to the stability of the 2-stranded alpha-helical coiled-coil, Biochemistry, 1992, 31, 5739-5746.

Supplemental Material: The online version of this article offers supplementary material (https://doi.org/10.1515/chem-2019-0004). 